\title{
Phosphate dynamics tied to sediment disturbances in Alfacs Bay (NW Mediterranean)
}

\author{
Montserrat Vidal \\ Departament d'Ecologia, Universitat de Barcelona, Diagonal 645, E^08028 Barcelona, Spain
}

\begin{abstract}
Field and laboratory experiments were performed on the sediments of an estuarine bay (Alfacs Bay, Spain, NW Mediterranean) to study the influence of sediment disturbances on phosphate dynamics. Massive release of soluble reactive phosphorus (SRP) from the sediment was found after $3 \mathrm{~h}$ of bell-jar incubations in resuspension conditions. Suspension of sediment particles in laboratory experiments showed fluctuating behaviour characterized by quick alternation between SRP retrieval from and release to the water under low SRP concentrations, and an exponential SRP decrease under high SRP concentrations. Besides raising SRP decay rates, resuspension of particles had the net effect of increasing SRP concentrations in the water column. The phosphate dynamics in resuspension conditions is explained on the basis of 2-step sorption and P-buffer exchange mechanisms. These are discussed in the scope of the processes involved (biotic and abiotic SRP uptake), nitrogen and phosphorus budgets in Alfacs Bay, phosphorus availability, and the survival of phytoplankton populations. Furthermore, the role of sediments in periodic storage of nutrients coupled to hydrodynamic conditions is addressed.
\end{abstract}

KEY WORDS: Phosphorus - Adsorption/desorption - Suspended sediments - Sediment-water fluxes . Estuaries $\cdot$ Mediterranean Sea

\section{INTRODUCTION}

Accumulation of materials and restricted transport in the sedimentary environment of enhanced biological, physical and chemical processes modifies the composition of the water entrapped in the solid material, leading to the establishment of exchange mechanisms between this solution and its surroundings. Transport processes depend on whether or not sediments are disturbed.

Most available data on sediment-water nutrient fluxes concern exchanges through an undisturbed top sediment layer, and were largely obtained at standard levels of water motion, because of difficulties in reproducing environmental conditions. Nevertheless, sediment disturbances are a characteristic feature of shallow waters that can strongly influence the exchanges between the sediment and the water (Holdren \& Armstrong 1980, De Groot 1981, Kelderman 1984). The chief effect of these perturbations is the enhancement of solid-solution interactions, with great consequences for the behaviour of those chemicals, like phosphorus, that have a strong affinity for particles.
Suspended sediments have long been known to influence concentrations of dissolved phosphorus. Dissolved phosphate concentrations in many estuaries are maintained within a narrow range by adsorption/desorption reactions involving particles (Pomeroy et al. 1965, Butler \& Tibbitts 1972, van Bennekom et al. 1978, Morris et al. 1981, Sharp et al. 1982, Fox et al. 1985, 1986, Froelich 1988, Lebo 1991). This 'buffering' effect was first suggested by Carritt \& Goodgal (1954), and since then it has been examined extensively with respect to the kinetics, equilibrium and reversibility of the adsorption/desorption reactions (Barrow 1983, Crosby et al. 1984, Bolan et al. 1985, Froelich 1988, Fox 1989, Brinkman 1993), the sorption capacity of suspended sediments (Lijklema 1980, Lucotte \& d'Anglejan 1988, Carman \& Wulff 1989), and the mineral phases involved (Chen et al. 1973, Huang 1975, Bowden et al. 1980, Lijklema 1980, Carpenter \& Smith 1984, Crosby et al. 1984). These studies suggest that, in shallow water sediments, control of phosphate release by diffusion is likely to be less important than control by dynamic 
sorption, mineralogical exchanges or mixing processes (Krom \& Berner 1980, Holdren \& Armstrong 1980). In estuarine suspended and bottom sediments, particle-bound phosphorus has been found to be associated with organic matter and phases of iron, aluminum, and calcium (Upchurch et al. 1974, Lucotte \& d'Anglejan 1983, Rehm 1985, Strom \& Biggs 1982, Lebo 1991).

The great capacity of sediment surfaces to adsorb phosphate has posed the question of the availability of phosphorus for algae and bacteria. Suspended sediments may release and/or sequester phosphate, so that the algae undergo greater nutrient limitation (Heath \& Francko 1988). In fact, the short-term effects of suspended sediment lead to effective competition among phytoplankton species and sediment particles for dissolved nutrients such as phosphate, and can also determine a change in the community structure and physiology (Avnimelech et al. 1982, Cuker et al. 1990, Burkholder 1992).

This paper studies Alfacs Bay (Spain, NW Mediterranean) sediments to assess the role of sediments as a source/sink for dissolved phosphate. Consequently, an attempt has been made to evaluate soluble reactive phosphorus (SRP) exchanges between sediments and water and to assess the effect of sediment disturbances on these exchanges.

Sediment disturbances are particularly notable in the shallow platforms of Alfacs Bay, through which freshwater comes into the Bay (on the northern platform). The proximity of nutrient-rich freshwater and sediments raises the question of the fate of these nutrients and suggests that sediments could have a key influence on nutrient concentrations in the water column. This applies especially to phosphorus, which shows lower concentrations in the water near discharge channels (Delgado \& Camp 1987, Vidal 1991) and lower values of release from sediments relative to nitrogen (Vidal et al. 1989, Vidal 1991). In addition, previous studies on sediment-water nutrient fluxes in Alfacs Bay point to resuspension as a determinant of phosphorus availability in the water column (Vidal et al. 1989).

\section{MATERIAL AND METHODS}

Alfacs Bay is a shallow estuarine bay $(3 \mathrm{~m}$ mean depth) at the south side of the Ebro River Delta complex, from which it receives freshwater from MarchApril to October-November, through discharge channels that flow out onto its northern platform $<1.5 \mathrm{~m}$ in depth). Three stations were chosen: Stns $1 \& 3$ on the northern platform and Stn 5 on the northern cuvette, due to their distinctive sediment characteristics (Stn 1: sandy; Stn 3: sandy-muddy; Stn 5: muddy). Characteristics of the Bay and the sampling stations are described in more detail in Camp \& Delgado (1987), Prat et al. (1988), Vidal (1991), Vidal et al. (1992).

Experiments were designed to study phosphorus behaviour under different degrees of water motion and sediment disturbance.

In situ experiments. Sediments at Stns 1 \& 3 were incubated in the field on 4 and 5 June 1987 under dark bell-jars in a sequence of increasing water motion conditions. The incubation chamber has a $700 \mathrm{~cm}^{2}$ circular base and $7 \mathrm{l}$ volume (Fig. 1). To avoid sediment resuspension, the bell-jar installation was done by carefully placing the incubation chamber over a ring with a $6 \mathrm{~cm}$ sharpened edge that had been previously introduced into the sediment. Water samples were taken at the start and at the end of each $3 \mathrm{~h}$ incubation period. An inner polyethylene bag was filled with outside water to compensate for changes in volume during the withdrawal of samples. The incubation procedure is described in more detail in Vidal et al. (1989).

The water motion sequence was established by means of electrical water pumps working at different

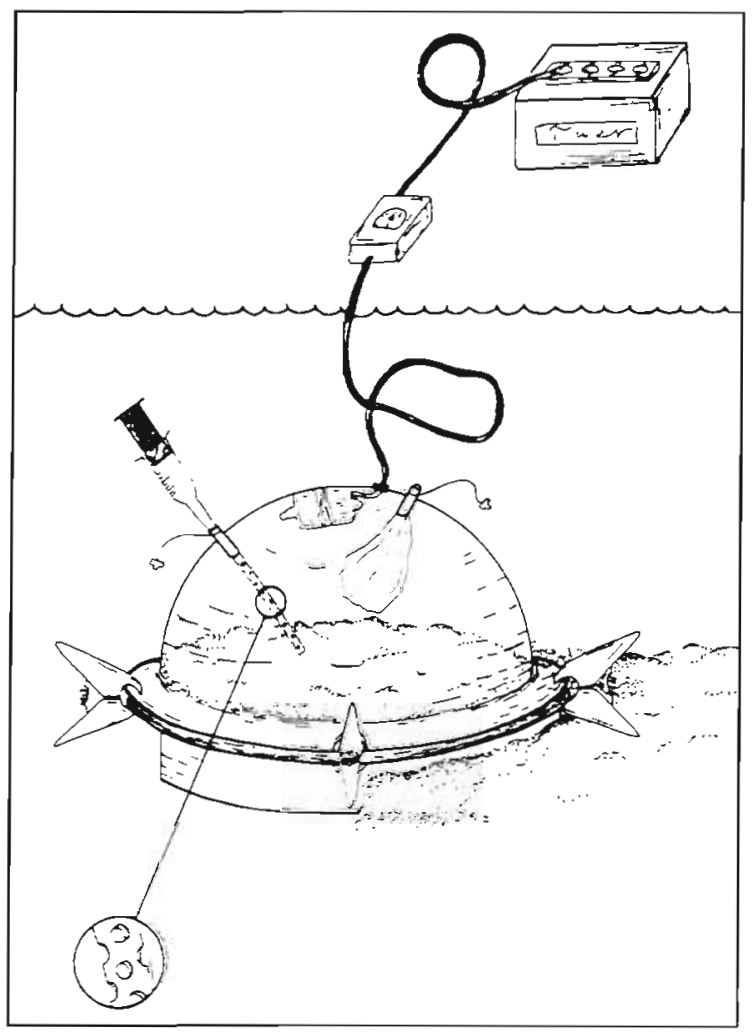

Fig. 1. Benthic flux chamber used in this study showing the ring half-embedded in the sediment, the sampling syringe, the stirring device with the battery, and the plastic bag for volume compensation 
intensities. Six experimental conditions were considered: (1) no stirring; (2) minimal stirring, like the standard used in the seasonal sampling program (Vidal 1991); (3 \& 4) moderate stirring without sediment resuspension; $(5 \& 6)$ vigorous stirring leading to sediment resuspension. Unfortunately, accurate calibration of the flow speeds inside the bell-jars was not possible, so that stirring intensities (1 to 6 ) will only provide a qualitative approach.

Dissolved oxygen and ammonium and soluble reactive phosphorus (SRP) concentrations were analyzed using the Winkler and the standard colorimetric methods described in Grasshoff et al. (1983).

Laboratory experiments. Laboratory experiments were performed on sediment samples taken from Stn 5 and occasionally from Stn 1 by carefully pushing down methacrylate cylinders ( $7 \mathrm{~cm}$ i.d., $40 \mathrm{~cm}$ long) into the sediment. Each sample consisted of $10 \mathrm{~cm}$ of sediment, the remainder of the cylinder being filled with water from the same location. Rubber stoppers prevented water displacement inside the cylinder. Samples were left in a refrigerator until the start of the experiments. Experiments were run in the dark, at constant temperature of about $18^{\circ} \mathrm{C}$ and under saturated oxygen atmosphere. Cylinders were replenished with filtered (Whatman $0.45 \mu \mathrm{m}$ followed by Millipore $0.2 \mu \mathrm{m}$ ) seawater collected at each location, and left to reach equilibrium at the above-mentioned conditions $1 \mathrm{~d}$ before the start of the experiments.

Water motion in the sediment cylinders was attained through air bubbling inside a methacrylate tube $(3 \mathrm{~cm}$ i.d.) hung on the top edge of the cylinder (Fig. 2). Ascension of air bubbles along the inner tube induced circulation of the water. Both downward displacement of this tube and increased rate of bubbling enhanced water stirring to produce sediment resuspension.

Two series of laboratory experiments were undertaken: (A) non-P-added experiments, to study SRP behaviour at low SRP concentrations $(0.1$ to $0.3 \mu \mathrm{M})$ and (B) P-added experiments, to inquire into the fate of the phosphate transported by inflowing freshwater, in which the concentration of SRP was high (1 to $4 \mu \mathrm{M})$.

The experimental set-up for non-P-added and Padded experiments involved the incubation of: (1) sediment cylinders in conditions of gentle motion; (2) continuously resuspended sediment cylinders; and (3) suspensions of sediment particles in glass vessels filled with filtered seawater (Fig. 2). Experimental controls on sediment-free cylinders and glass vessels showed that the incubation flask did not affect SRP concentrations in the water (e.g. by wall-related processes).

In each series ( $\mathrm{P}$-added and non-P-added), 2 core replicates were used for each experimental condition (gently stirred, resuspended corers and particle suspensions). Concentration of particles in the suspension

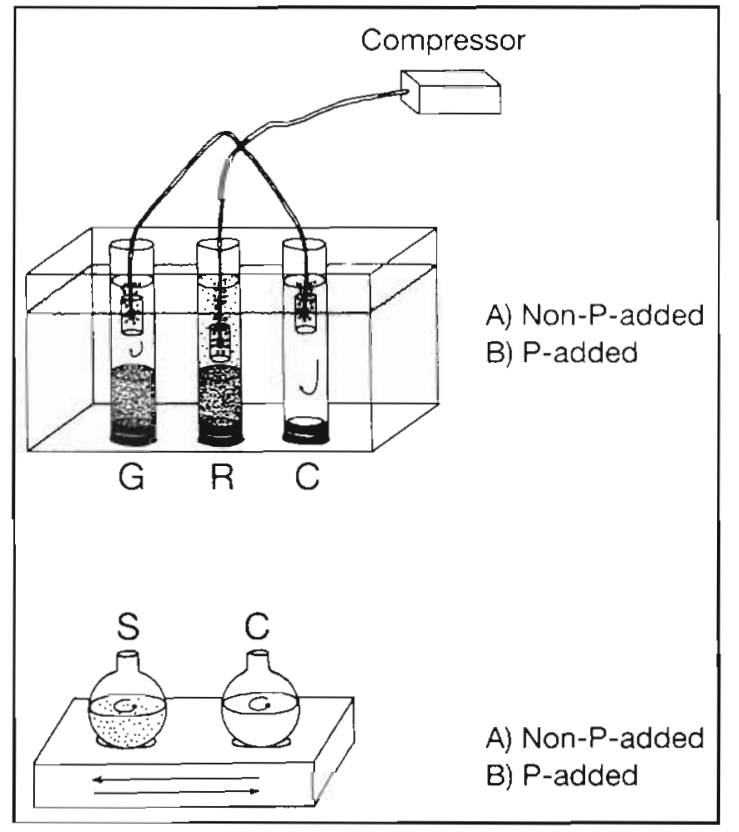

Fig. 2. Experimental set-up used in the laboratory experiments, with the water motion system. G: sediment cylinders in gentle water motion conditions; R: continuously resuspended sediment cylinders; $\mathrm{S}$ : suspension of sediment particles in glass vessels; $C$ : sediment-free experimental controls. Two series of experiments were undertaken: $(A)$ without $P$ added and $(\mathrm{B})$ with $\mathrm{P}$ added

replicates was identical, though it was different in the core replicates undergoing resuspension, leading in some cases to very different particle concentrations in the water. For this reason, 4 core replicates were included in the non-P-added resuspended experiments and particle concentrations increased, as a result of increased stirring, in one of them.

Suspensions of fresh sediment particles (taken from a homogenized slice of 0 to $0.5 \mathrm{~cm}$ in depth) were kept on a moving plate during the incubations. Experiments were continued as long as significant concentration changes were detected, which ranged from a few hours to several days for the continuously resuspended, gently stirred cylinders and particle suspensions, respectively.

Phosphate solution $\left(\mathrm{KH}_{2} \mathrm{PO}_{4}\right)$ was used in P-added experiments to final concentrations of 3 to $4 \mu \mathrm{M}$, to reproduce maximum values found in freshwater discharge channels.

Water samples $(15 \mathrm{ml})$ were taken periodically during the experiment with a plastic syringe provided with a tube, immediately filtered (through Millipore HAWP02500 filters) and cooled $\left(4^{\circ} \mathrm{C}\right)$. SRP concentrations were analyzed 1 to $4 \mathrm{~h}$ after sampling, by the standard procedure mentioned above. Particle concentration in solution was determined after the weighing of dry filters $\left(105^{\circ} \mathrm{C}, 24 \mathrm{~h}\right)$. 
Numerical transformation. Data on P-added experiments were used in 2 ways. (1) SRP decay rates $(k)$ were computed from SRP concentrations against time plots using an exponential decay equation: $\mathrm{SRP}_{i}=$ $\mathrm{SRP}_{0} \mathrm{e}^{-k t}$. From this equation, the half-life of SRP in the water was also calculated. (2) Solid-solution SRP exchanges were computed from consecutive SRP concentration changes versus elapsed time. From the linear regression of these exchange rates to the starting SRP concentration of each time interval, 2 parameters were considered: SRP exchange rates when SRP concentrations in the water was zero (SRPflux $_{S R P=0}=$ intercept values), and SRP concentrations in the water that determined null exchange rates. The latter can be considered analogous to an equilibrium phosphate concentration (EPC, sensu Froelich 1988), at which the rate of the forward reaction (SRP retrieval from the water) and the reverse reaction (SRP release to the water) are the same. What follows will be referred to as EPC values. All these parameters $(k$, half-life SRP, SRP-flux $\mathrm{SRP}_{\mathrm{S}=0}$ and EPC values) were computed from data of P-added gently, resuspended corers and particle suspensions. From the log-log plot of SRP solid-solution exchanges against time, the instantaneous SRP adsorption was also computed.

Data from non-P-added experiments obtained in resuspension conditions were used as follows: portions of data sets showing at least 3 successive decreasing values were selected, and exchange rates were calculated (as mentioned above) and related to the initial SRP concentrations. From this relationship SRP-flux $x_{S R P=0}$ and EPC were computed.

\section{RESULTS}

\section{In situ experiments}

Fig. 3 shows the course of oxygen-uptake, ammonium and SRP release from the sediments following the increase in water stirring conditions. Gentle stirring (bell-jars 2 to 4 ) had slight (from 0 to $6 \mu \mathrm{mol}$ $\mathrm{m}^{-2} \mathrm{~h}^{-1}$, at Stn 3) or null (Stn 1, which always showed null or even negative fluxes) effects on sediment SRP release. To the contrary, sediment resuspension (belljars 5 \& 6) greatly enhances SRP concentrations in the bell-jar water up to values of 0.4 to $0.5 \mu \mathrm{M}$ (Stn 1) and 1.5 to $4 \mu \mathrm{M}$ (Stn 3 ), equivalent to sediment SRP releases of 10 and 42 to $140 \mu \mathrm{mol} \mathrm{m} \mathrm{m}^{-2} \mathrm{~h}^{-1}$, respectively.

When comparing stagnant (bell-jar 1) and stirred conditions (bell-jar 2) large differences were found in oxygen-uptake and ammonium release. Subsequent increases in water stirring (bell-jars 3 \& 4), without achieving resuspension, had minor effects on fluxes, except for sediment oxygen uptake at $\operatorname{Stn} 3$, which showed progressive enhancement. Sediment resuspension (bell-jars $5 \& 6$ ) led to a second steep increase in flux.

Differences in the pattern of enhancement in oxygenuptake and ammonium release as stirring increases at station 3 led to changes in the $\mathrm{O}_{2}: \mathrm{NH}_{4}{ }^{+}$ratios, from 20:1 in non-stirred and gently stirred bell-jars, to $40: 1$ in vigorous stirring bell-jars. At $\operatorname{Stn} 1$, this ratio was always around 50:1. $\mathrm{NH}_{4}{ }^{+}$: $\mathrm{SRP}$ ratios in fluxes at both stations fall from above $30: 1$ in gentle stirring conditions to below 10:1 in resuspension conditions.

\section{Laboratory experiments}

\section{Non-P-added experiments}

Fig. 4 shows SRP concentrations inside 4 continuous resuspended sediment cylinders with different particle concentrations in the water (insets of each graph). A
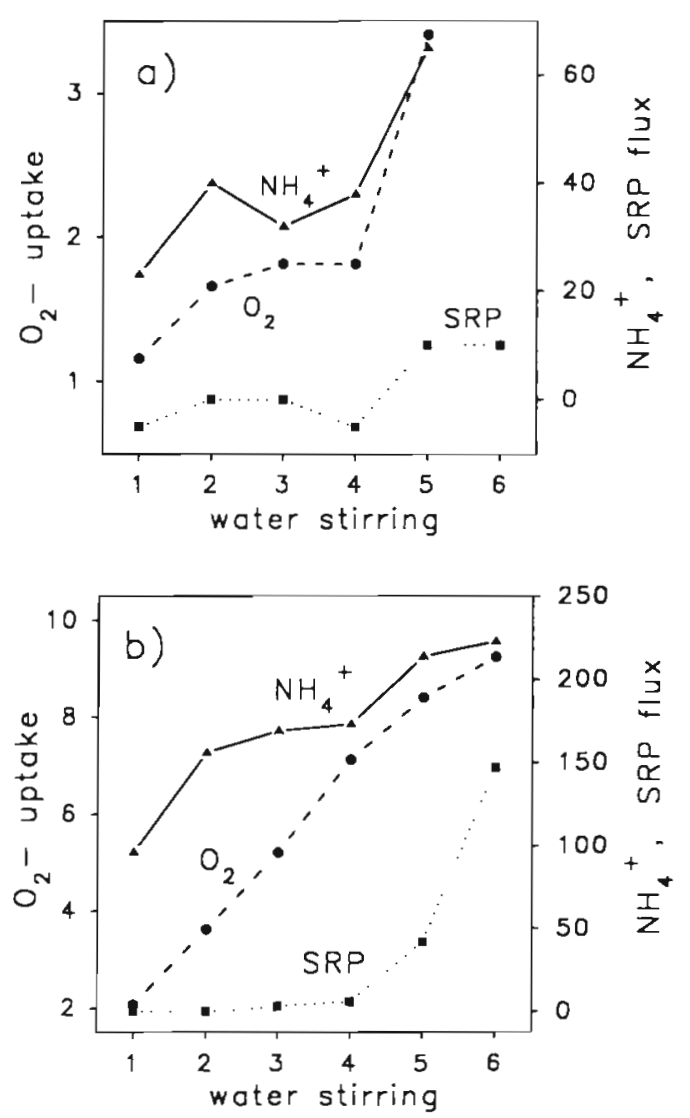

Fig. 3. Course of oxygen uptake (as mmol $\mathrm{m}^{-2} \mathrm{~h}^{-1}$ ), ammonium and SRP fluxes (as $\mu \mathrm{mol} \mathrm{m}^{-2} \mathrm{~h}^{-1}$ ) from field bell-jar incubations in a sequence of water stirring conditions, expressed as relative values. 1 : without stirring; 2 : minimal stirring; $3 \& 4$ : moderate stirring; 5 \& 6 : vigorous stirring. (a) $\operatorname{Stn}$ 1. (b) $\operatorname{Stn} 3$ 
Fig. 4. Time course of SRP concentrations (as $\mu \mathrm{M}$ ) in 4 (a to d) non-P. added resuspended corers, with different particle concentrations in the water (as $g$ dry wt $l^{-1}$, in the inset of each graph). (O) in (a): time course of SRP concentrations under gently stirred conditions
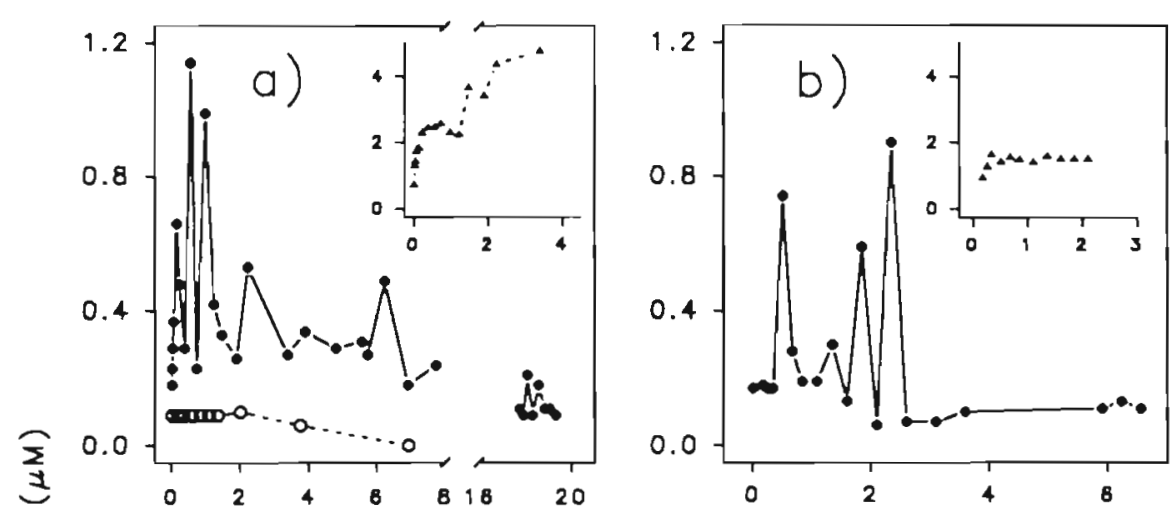

$\frac{a}{\alpha}$

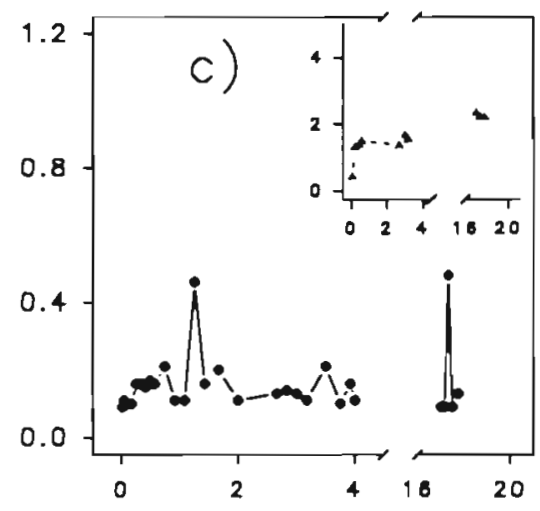

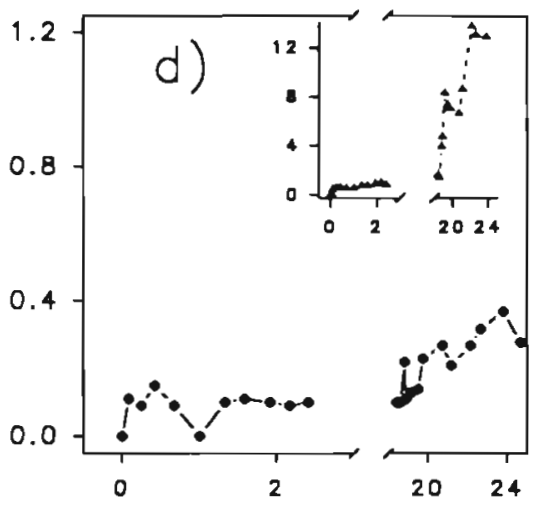

time (h) pattern of tight SRP peaks and troughs was observed in most of the experiments. SRP rose to $0.7 \mu \mathrm{M}$ following the initial increase in particle concentration (from 0.5 to $2 \mathrm{~g} \mathrm{dry} \mathrm{wt}^{-1}$; Fig. 4a). However, high SRP values lasted for a short time (minutes) and SRP quickly disappeared. SRP peaks and troughs were also noticeable following small changes in particle concentrations (from 1.5 to $2 \mathrm{~g}_{\text {dry }}$ wt $\mathrm{l}^{-1}$; Fig. $4 \mathrm{~b}$ ). SRP shifts were less frequent at the end of the experiments, leading to final SRP concentrations of around 0.2 to $0.3 \mu \mathrm{M}$. These values are greater than those observed in the gently stirred core (Fig. 4a), in which SRP concentrations became undetectable.
Similar SRP changes to the above-mentioned were also observed in the 2 particle suspension experiments (Fig. 5).

\section{P-added experiments}

SRP decreased in all P-added experiments (gently stirred, resuspended corers and particle suspensions), soon after the addition of the phosphate solution (Fig. 6). Time course of residual SRP was exponential (see 'Material \& methods: Numerical transformations') with different decay rates $(p<0.01)$ depending
Fig. 5. Time course of SRP concentrations (as $\mu \mathrm{M}$ ) in 2 non-P-added particle suspensions, with particle concentrations of (a) $0.74 \pm 0.02 \mathrm{~g}$ dry wt $1^{-1}$ and (b) $0.69 \pm 0.06 \mathrm{~g}$ dry wt $1^{-1}$
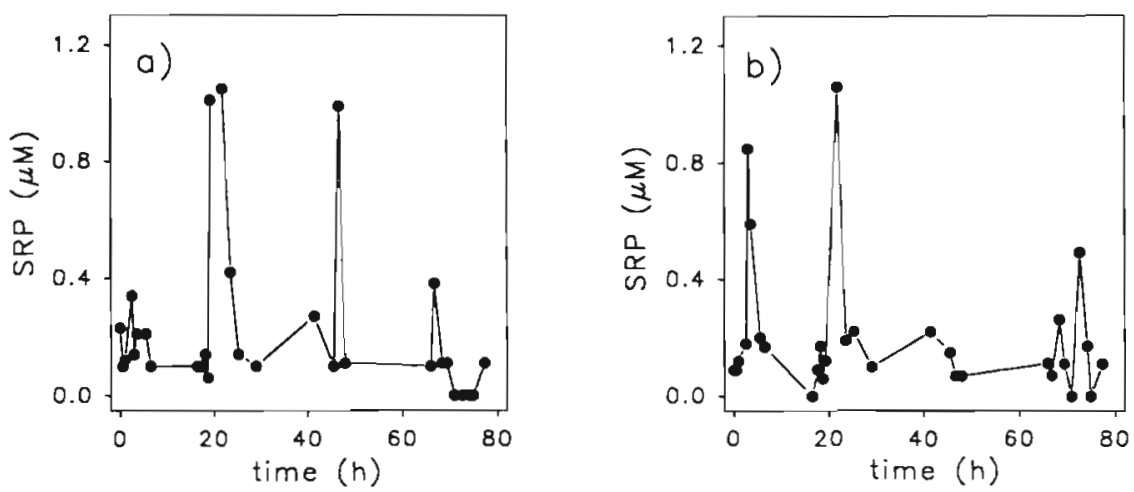
on experimental condition (Table 1). From these rates, the half-life of SRP in the water is $77 \mathrm{~h}$, 14 to $17 \mathrm{~h}$ and $7 \mathrm{~h}$ in particle suspensions, gently stirred and resuspended sediment cylinders, respectively.

\section{DISCUSSION}

From the results a picture of phosphorus dynamics through Alfacs Bay sediments can be drawn as follows. (1) Sediment to water SRP fluxes in moderate water stirring conditions are low compared to ammonium fluxes (Fig. 3), in agreement with previous data (Vidal et al. 1989). Null SRP fluxes in bell-jar experiments mean that values are below $3 \mu \mathrm{mol} \mathrm{m} \mathrm{m}^{-2} \mathrm{~h}^{-1}$, which is the detection limit of the assay. (2) Sediment resuspension determines a massive release of SRP (Fig. 3), and can lead to a change from phosphorus to nitrogen limitation (from $\mathrm{NH}_{4}^{+}$:SRP ratios in bell-jar fluxes). (3) Besides fostering SRP release to solution, resuspension of particles also promotes SRP removal from solution (Figs. 4 \& 5).

(4) Sediments, whether undisturbed or suspended, have a strong capacity to take-up SRP from the water (Fig. 6). (5) SRP decay rates are enhanced in resuspension conditions, as has been mentioned in other studies (see Table 1).

From bell-jar data (Fig. 3) SRP fluxes appear to be unaffected by the increase in stirring (without sediment resuspension). This suggests that SRP fluxes under stagnant conditions are not limited by the appearance of a layer with high SRP concentrations over the sediment. In contrast, the increase found in
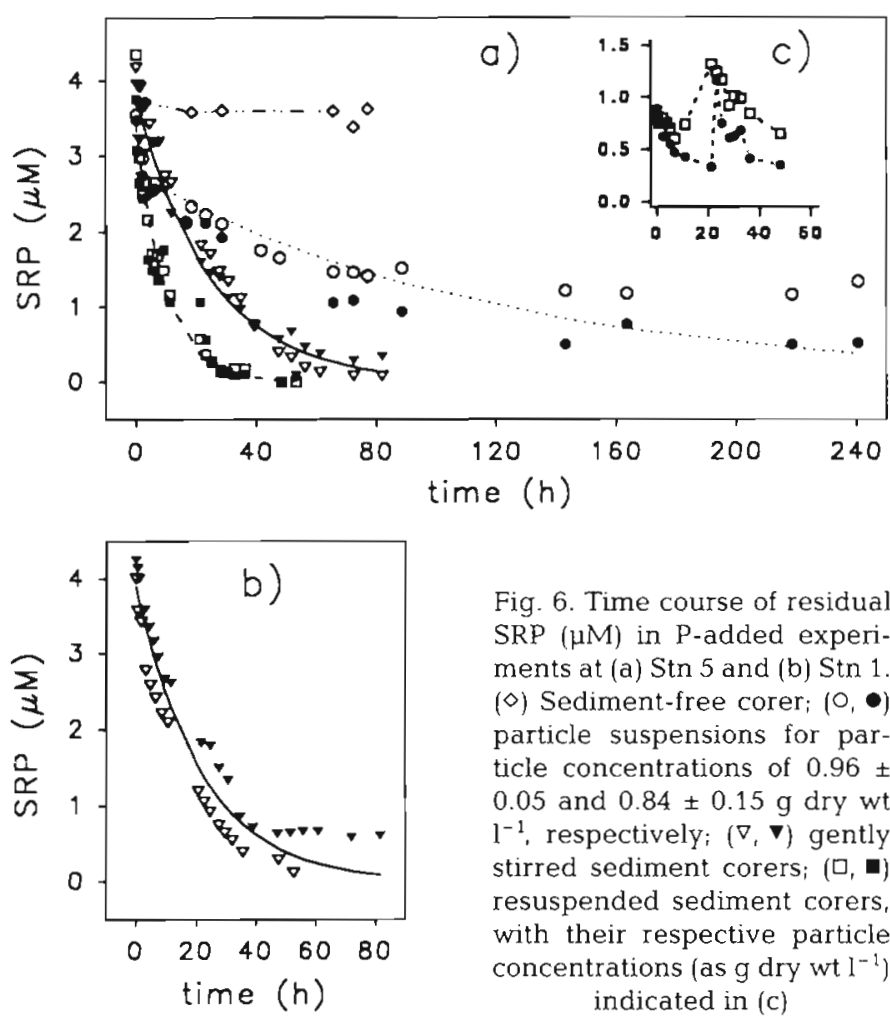

Fig. 6. Time course of residual SRP $(\mu M)$ in P-added experiments at (a) Stn 5 and (b) Stn 1. $(\diamond)$ Sediment-free corer; $(0, \bullet)$ particle suspensions for particle concentrations of $0.96 \pm$ 0.05 and $0.84 \pm 0.15 \mathrm{~g}$ dry wt $\mathrm{l}^{-1}$, respectively; $(\nabla, \nabla)$ gently stirred sediment corers; $(\square, \square)$ resuspended sediment corers, with their respective particle concentrations (as g dry wt $\mathrm{I}^{-1}$ ) indicated in (c)

both oxygen-uptake and ammonium release following the change from stagnant to circulating water may be related to the breakdown of a high ammonium / low oxygen concentration stagnant layer. This would be achieved at a low level of stirring (bell-jar 2) and would explain the almost invariant values of oxygen uptake (at Stn 1) and ammonium release (at Stns 1 \& 3) found following the subsequent increases in water stirring (bell-jars $3 \& 4$ ). The steady increase in oxygen uptake

Table 1. SRP decay rates $\left(k, h^{-1}\right)$ and half-life times $(h)$ obtained from this study compared to values from the literature. S: suspensions; G: gently stirred; R: resuspended corers. Particle concentrations in $\mathrm{g} d r y$ wt $\mathrm{l}^{-1}$. Values in parentheses indicate starting SRP concentrations of the various experiments

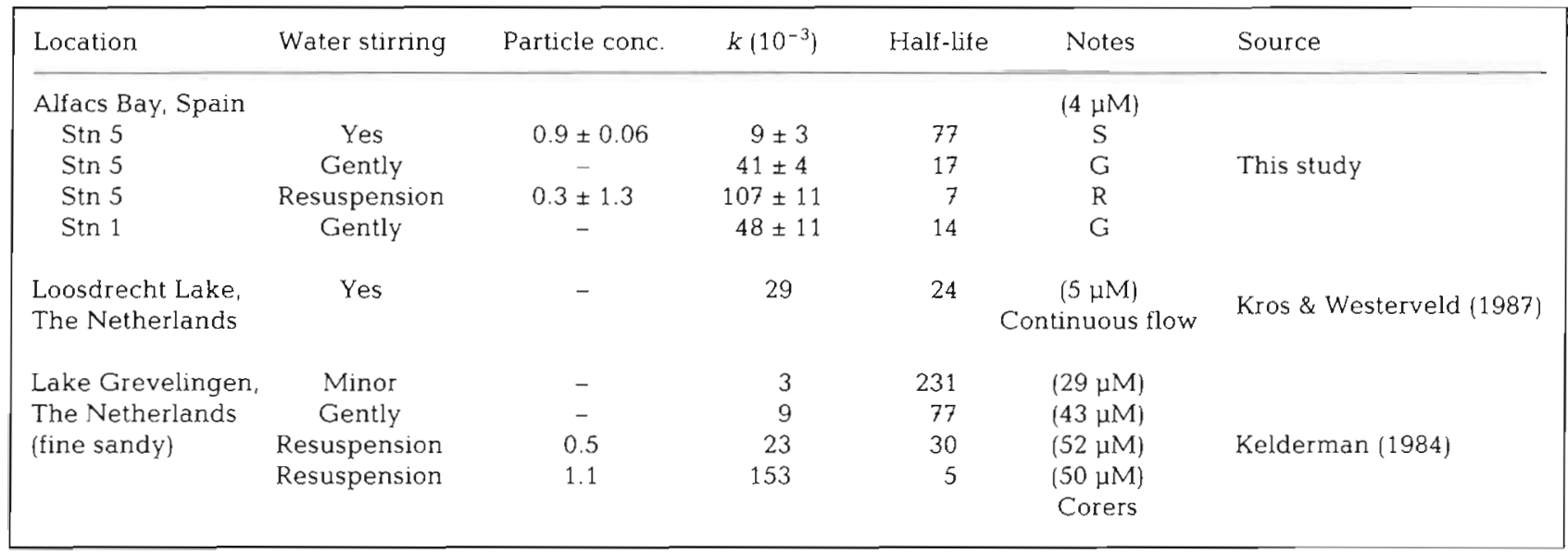


found at Stn 3 can be related to its high metabolism, as was shown by the high values of oxygen uptake determined. Anaerobic metabolism was probably high, determining the migration of chemically reduced compounds from the sediment to the water and the depletion of oxygen in the benthos. In these conditions, the increase in oxygen concentrations in the bottom water after an increase stirring can cause an increase in oxidation and/or the respiration of benthic organism, thus determining an increase in the overall sediment oxygen uptake (Davies 1975, Boynton et al. 1981).

The decrease in oxygen uptake and ammonium release under stagnant conditions agrees with that found in other studies, which has been interpreted as being due to the effect of the stagnant benthic boundary layer in diminishing the sediment-water diffusive fluxes, based on concentration gradients (Morse 1974, Jørgensen \& Revsbech 1985, Hall et al. 1989, Rahm \& Svensson 1989, Gundersen \& Jørgensen 1990). The lack of this effect of water circulation on SRP-fluxes suggests some 'P-buffer' mechanism superimposed to diffusion from the sediments, which prevents high SRP concentrations in the water overlying the sediment in the bell-jar experiments.

It has generally been accepted that desorption of SRP from sediment surfaces is the main process responsible for the increase in SRP concentrations often found in sediment resuspension events (Holdren \& Armstrong 1980, De Groot 1981, Peters \& Cattaneo 1984, Hamilton \& Mitchell 1987, Bostrom et al. 1988, Froelich 1988). This mechanism could explain the high SRP fluxes found in the vigorously stirred bell-jars. Nevertheless, dissolved phosphate has a characteristic short residence time in the water, mainly due to the rapid uptake by algae and bacteria and to the high affinity of phosphate for particles (Pomeroy 1960). Partitioning between biotic and abiotic SRP uptake can be variable and depend on environmental conditions (Burkholder 1992), although its overall effect is a rapid decrease in SRP concentrations in the water. Biological SRP uptake cannot be ruled out from the laboratory experiments, since the sediments had not been sterilized. Nutrient uptake of phytoplankton in the dark and uptake of nutrients by heterotrophic organisms are well known (Parsons et al. 1984), so that some SRP uptake, such as that due to benthic diatoms and heterotrophic bacteria, could be expected to occur in these experiments. Taking the experimental conditions into account, heterotrophic organisms could contribute to a great extent in the biological SRP. uptake, since their growth could be enhanced by the high organic carbon concentrations that follow the resuspension of sediments (Hamilton \& Mitchell 1987). In fact, primary production of microphytobenthos in these sediments accounts for about $45 \mathrm{mg} \mathrm{C} \mathrm{m} \mathrm{m} \mathrm{d}^{-1}$ (Delgado 1989). Bacterial production for a $1 \mathrm{~cm}$ layer of sediment was between 200 and $350 \mathrm{mg} \mathrm{C} \mathrm{m}^{-2} \mathrm{~d}^{-1}$, calculated from data of $\left[{ }^{3} \mathrm{H}\right]$ thymidine incorporation (0.09 nmol $\mathrm{g} \mathrm{dw}^{-1} \mathrm{~h}^{-1}$ in the muddy organic rich sediments of Alfacs Bay; Mallo et al. 1993) converted into cells and carbon units by applying the factors
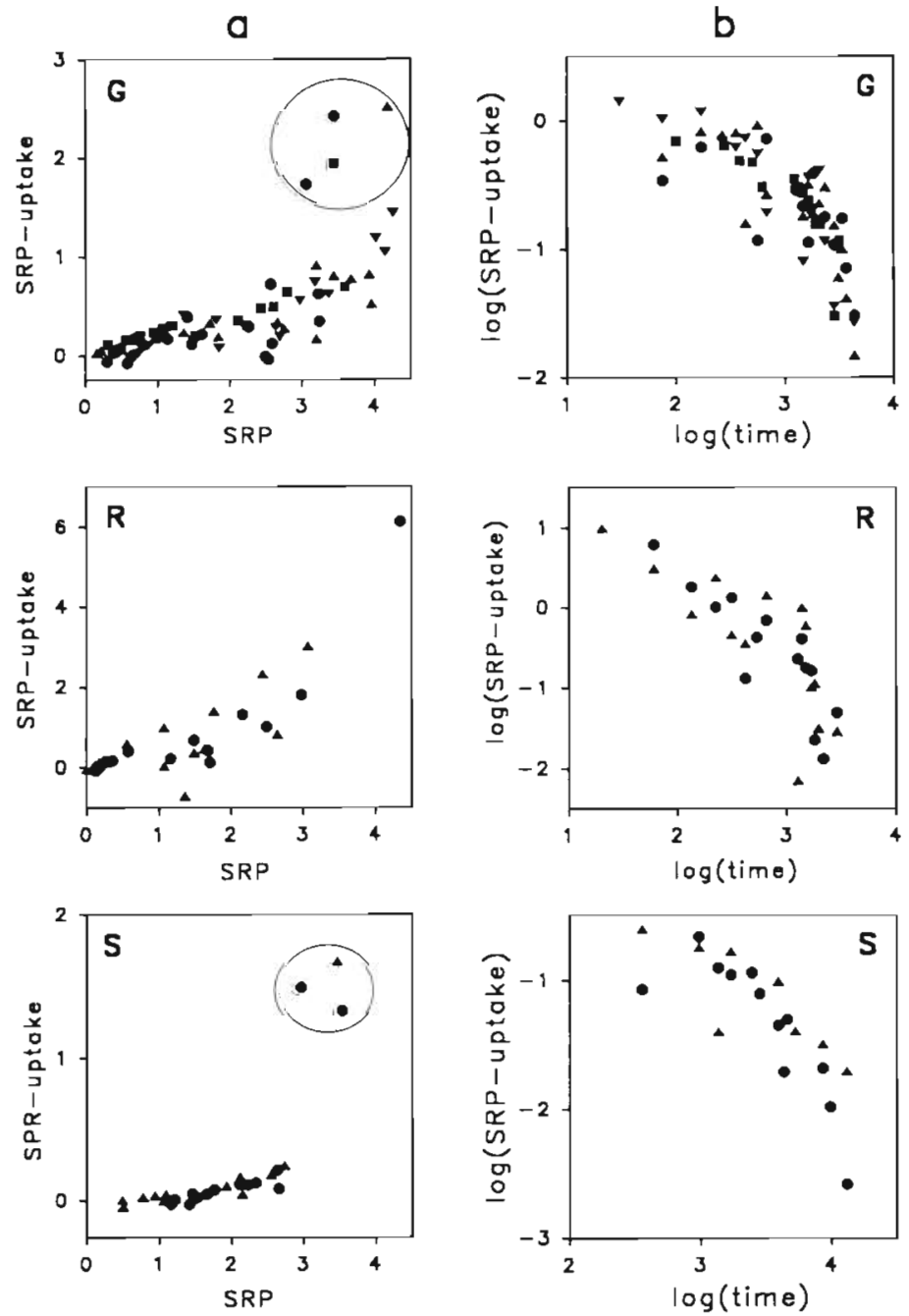

Fig. 7. SRP uptake rates from P-added experiments: (a) against SRP concentrations and (b) against time, after logarithmic transformation. Uptake rates are in $\mu \mathrm{mol} \mathrm{m} \mathrm{min}^{-2}$, concentrations in $\mu \mathrm{M}$ and time in min. G: gently stirred corers; R: continuously resuspended corers; S: particle suspensions. $(\bullet, \mathbf{\Delta})$ The 2 replicates at $\operatorname{Stn} 5 ;(\boldsymbol{\nabla}, \boldsymbol{\bullet})$ the 2 replicates for Stn 1. Symbols within circle in (a) are the values excluded from linear regressions 
Table 2. Parameters obtained in fitting data on P-added experiments to the linear equation $y=b+m x$. G: gently stirred corers: R: resuspended corers; S: particle suspensions. Numbers in Expt column refer to Stns 1 \& 5 . Parameters from the 2 replicates of each experiment are presented. - Data from non-P-added resuspended experiments (see explanations in text)

\begin{tabular}{|c|c|c|c|c|c|c|}
\hline Expt & $b$ & SE & $m$ & SE & $r^{2}$ & $\mathrm{p}$ \\
\hline \multicolumn{7}{|c|}{ SRP uptake rates versus SRP concentrations (Fig. 7a) } \\
\hline G5 & -0.009 & 0.086 & 0.122 & 0.046 & 0.304 & 0.0178 \\
\hline G5 & -0.014 & 0.067 & 0.174 & 0.028 & 0.688 & 0.0000 \\
\hline $\mathrm{G} 1^{\mathrm{d}}$ & -0.228 & 0.079 & 0.298 & 0.032 & 0.830 & 0.0000 \\
\hline G1 & 0.042 & 0.030 & 0.177 & 0.016 & 0.908 & 0.0000 \\
\hline R5 & -0.552 & 0.326 & 1.048 & 0.181 & 0.721 & 0.0001 \\
\hline R5- & -0.207 & 0.249 & 0.708 & 0.169 & 0.557 & 0.0009 \\
\hline S5 & -0.140 & 0.032 & 0.113 & 0.017 & 0.779 & 0.0000 \\
\hline S5 & -0.077 & 0.027 & 0.098 & 0.016 & 0.803 & 0.0000 \\
\hline$\cdot$ & -1.908 & 2.061 & 11.267 & 3.620 & 0.618 & 0.0208 \\
\hline \multicolumn{7}{|c|}{$\log ($ SRP uptake rates) versus $\log$ (time) (Fig. $7 b)$} \\
\hline G5 & 0.682 & 0.504 & -0.457 & 0.161 & 0.402 & 0.0149 \\
\hline C.5 & 1.483 & 0.475 & -0.710 & 0.155 & 0.567 & 0.0003 \\
\hline G1 & 2.102 & 0.591 & -0.967 & 0.199 & 0.596 & 0.0002 \\
\hline G1 & 1.376 & 0.419 & -0.660 & 0.139 & 0.654 & 0.0005 \\
\hline R5 & 3.073 & 0.627 & -1.278 & 0.218 & 0.741 & 0.0001 \\
\hline R5 & 2.439 & 0.703 & -1.062 & 0.251 & 0.598 & 0.0012 \\
\hline S5 & 2.086 & 0.792 & -0.990 & 0.226 & 0.657 & 0.0014 \\
\hline S5 & 1.093 & 0.593 & -0.657 & 0.172 & 0.708 & 0.0088 \\
\hline
\end{tabular}

Table 3. Equilibrium phosphate concentration, EPC (SRP concentrations at null net exchange rates, as $\mu M$ ), SRP-flux $\operatorname{SRP}_{\mathrm{S}=0}$ (SRP release from the sediment when SRP concentrations in the water are equal to zero, as $\mu \mathrm{mol} \mathrm{m}^{-2} \mathrm{~h}^{-1}$ ), and instantaneous SRP-adsorption (as $\mathrm{mmol} \mathrm{m} \mathrm{m}^{-2} \mathrm{~h}^{-1}$ ). computed from data on P-added experiments

\begin{tabular}{|lccc|}
\hline & Gently stirred & Resuspended & P suspensions \\
\hline EPC & 0.1 & $0.2-0.6$ & 1.0 \\
SRP-flux & $0.5-0.8$ & $12.0-33.0$ & $5.0-8.0$ \\
Instant SRP adsorp. & $0.3-1.8$ & $16.5-71.1$ & $0.7-7.3$ \\
\hline
\end{tabular}

ment resuspension, and may explain the SRP peaks observed in the non-P-added resuspended experiments (Figs. 4 \& 5). Moreover, the succession of SRP peaks observed and their attenuation over time suggests some controlling mechanism. To search for the kinetics of the SRP exchanges, data on Padded experiments were used following the same approximation as that explained in the numerical transforms section.

\section{Kinetic approach}

To study the kinetics of SRP withdrawal from solution, uptake-rates versus SRP concentrations were pictured from data on Padded experiments (Fig. 7a). Linear regressions of uptake rates to SRP concentrations were found (Table 2). Equivalent line slopes between replicates, excluding 1 case that was omitted from mean computations (see Table 2), and different slopes between experimental conditions $(p<0.01)$ were obtained. Otherwise, intercept values are not significant. Nevertheless, averaged intercepts (SRP exchanges when SRP concentrations equal zero, SRP-flux $x_{S R P=0}$ ) and SRP concentrations that determine null net exchange rates (referred to as EPC values, see numerical transform section) were computed from the linear equations to allow for comparisons between experimental and field data (Table 3).

EPC computed from data on P-added gently stirred corers resemble SRP concentrations attained in non-P-added corers soon after the start of the incubations. Both values clearly compare with the SRP concentrations more frequently found in the Bay, where

$1.5 \times 10^{1.8}$ cells $\mathrm{mol}^{-1}$ (Bell \& Ahlgren 1987), and $1.2 \times$

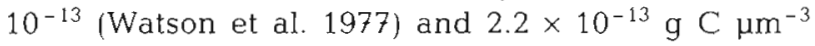
(Bratbak \& Dundas 1984), considering a cell volume of $0.1 \mu^{3}$ (Bell \& Ahlgren 1987). SRP decay from gently stirred P-added sediments could support a carbon assimilation of $933 \mathrm{mg} \mathrm{m}^{-2} \mathrm{~d}^{-1}$, calculated from an initial concentration of $4 \mu \mathrm{M}$ in the experiments and the $17 \mathrm{~h}$ half-life. From these data it appears that bacterial uptake could contribute 21 to $38 \%$ of the SRP decay in gently stirred conditions, in agreement with that found by other authors (see Gächter et al. 1988).

The combined effect of SRP desorption from sediment surfaces and the subsequent rapid SRP uptake determines short-term SRP pulses upon episodic sedi-
$45 \%$ of observations over a year were equal to or lower than $0.1 \mu \mathrm{M}$ (Vidal 1991). According to regression equations (Table $2 \mathrm{a}$ ), below $0.1 \mu \mathrm{M}$ sediments release

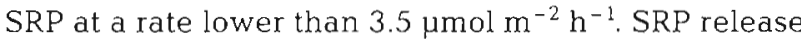
from the sediment was from 0.12 to $0.84 \mu \mathrm{mol} \mathrm{m} \mathrm{m}^{-2} \mathrm{~h}^{-1}$ at Stn 5, and from 0.14 to $0.35 \mu \mathrm{mol} \mathrm{m} \mathrm{m}^{-2} \mathrm{~h}^{-1}$ at Stn 1 (Vidal 1991, computed from Fick's first law of diffusion to SRP pore water profiles). These values are comparable to those calculated for the gently stirred corers from the linear equations, supposing SRP concentrations in the water are null (between 0.5 and $0.8 \mu \mathrm{mol}$ $m^{-2} h^{-1}$ Table 3)

Suspension of particles increases EPC values in both P-added resuspended sediment corers and particle suspensions (Table 3), as well as final SRP values in 


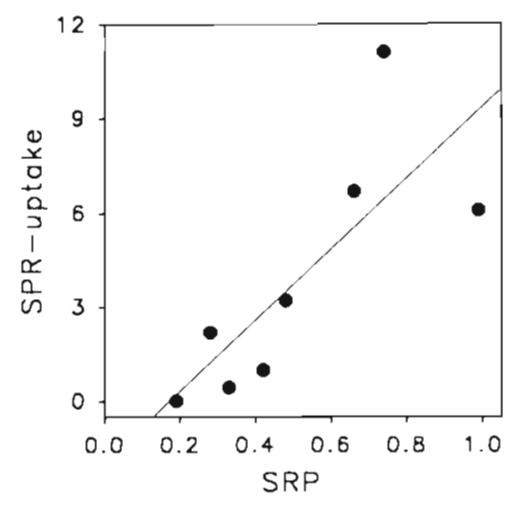

Fig. 8. SRP uptake rates $\left(\mu \mathrm{mol} \mathrm{m} \mathrm{m}^{-2} \mathrm{~min}^{-1}\right)$ from non-P-added resuspended corers against SRP concentrations $(\mu \mathrm{M})$. See explanations in text

non-P-added ones (Fig. 4), and close SRP values are achieved in both $\mathrm{P}$-added and non-P-added resuspended corers $(0.2$ to $0.6 \mu \mathrm{M})$. This means that, besides increasing SRP uptake rates (Table 1), suspension of particles has the net effect of enhancing SRP availability in the water. Higher EPC values in particle suspensions (Table 3) can be related to the saturation of adsorption sites (De Kanel \& Morse 1978, Crosby et al. 1984, Bolan et al. 1985), while more particle surfaces and a segment of the sediment column are involved in experiments with sediment corers. When comparing experimental and field data for resuspension conditions, agreement was also found between values of SRP release computed for null SRP concentrations in the water (from data on P-added corers, Table 3) and values obtained from resuspended bell-jars incubated in the field (10 and 42 to $140 \mu \mathrm{mol}$ SRP $\mathrm{m}^{-2} \mathrm{~h}^{-1}$ for Stns 1 \& 3, respectively; Fig. 3).

Fig. 8 shows SRP uptake rates from non-P-added resuspended corers plotted against SRP concentrations. A significant $(p<0.01)$ linear relationship was also found (Table $2 \mathrm{a}$ ). The EPC obtained $(0.17 \mu \mathrm{M})$ was comparable to EPC values from P-added experiments (in resuspension conditions; Table 3 ), while slope was greater. The linear equation describes kinetics in the low SRP concentration range, indicating that SRP uptake goes faster near equilibrium SRP concentrations, as has been stated by Froelich (1988).

\section{Phosphate dynamics in Alfacs Bay}

The relationship between SRP solid-solution exchanges and SRP concentrations in solution shown for Alfacs Bay sediments agrees with that found in other studies, which has been described in the scope of a phosphate buffer mechanism of widespread occurrence in natural waters. This mechanism is interpreted as the influence of sediments, whether benthic or suspended, in controlling the dissolved reactive phosphate concentrations in the water at some near constant value regardless of biological removal and input reactions (Carrit \& Goodgal 1954, Pomeroy et al. 1965, Edmond et al. 1985. Fox et al. 1985, 1986, Pilson 1985, Froelich 1988, Fox 1989, 1991).

Data presented here can be explained in terms of a phosphate buffer mechanism acting in Alfacs Bay sediments. Agreement between experimental and field data validates experimental results and gives support to this hypothesis. Otherwise, this mechanism helps to explain relevant aspects of phosphorus behaviour, especially those occurring in resuspension conditions. In such circumstances, fast SRP changes can be related to sorption/desorption reactions (Holdren \& Armstrong 1980, De Groot 1981, Peters \& Cattaneo 1984, Hamilton \& Mitchell 1987, Bostrom et al. 1988). According to Froelich (1988), delivery of sediment particles, kept in contact with interstitial solution, to a lower SRP solution determines that solids release phosphate for a short time (solid surface re-equilibrates with bulk solution), and then begin to take it up again (readjust to SRP concentration higher than equilibrium values). This mechanism explains the pattern of SRP concentration changes found in non-P-added experiments, in which SRP peaks and troughs alternate until equilibrium values are attained (Figs. $4 \& 5$ ). Continuous feeding of solution with new particles, from the sedimentary pool, could partly account for the fast SRP shifts in non-P-added resuspended corers, but not in particle suspensions, in which a fixed amount of solids was initially put into solution, so that adsorption/desorption processes onto particles provide a more realistic and general explanation to the observed pattern. Further, this mechanism could help to explain why sediment resuspension favours SRP release in some instances, while in others it seems to produce the opposite effect (Rippey 1977, Holdren \& Armstrong 1980, De Groot 1981). The closeness to EPC values (sensu Froelich 1988) in non-P-added experiments accounts for the fluctuating fast behaviour, in contrast to $\mathrm{P}$-added experiments in which a net sorption reaction prevails, because particles equilibrate with high SRP concentrations, near to interstitial values (from Vidal 1991) and far from equilibrium values. This environment allows the second-step of the sorption reaction to take place, through the slow penetration inside the particles, by solid-state diffusion, of the SRP firstly adsorbed on surfaces (Froelich 1988, Fox 1989), so that more SRP can be taken up from solution to adsorption sites.

The phosphorus dynamics described for Alfacs Bay compels us to treat nitrogen and phosphorus budgets in a different perspective, because the significance of the external inputs can be different for each one. Sediment ammonium release supplies nearly $80 \%$ of the 
phytoplankton requirements in Alfacs Bay, which, added to freshwater inputs, balances the whole nutritional need. The same argument for phosphorus suggests that inputs and requirements are unbalanced, since the SRP release from sediments added to the allochthonous inputs do not meet phosphorus requirements, and, hence that phosphorus is the primary limiting nutrient in this waters (Vidal 1991). The sediment control on SRP availability, as supported by this study, modifies those assertions, as long as sediments could counteract any SRP deficiency, provided some time lag for equilibration. Otherwise, the adsorption of a part of the SRP entering with the inflowing freshwater on the sediments $\left(C_{\text {org }}: P=62\right.$ and $N: P=8$ in the sediment of the nearest to discharge channel station; Vidal 1991) implies that the SRP input does not account actually for the budget but instead it becomes a part of the sedimentary pool. As a consequence, the question of the nutrient limitation in Alfacs Bay does not have a single answer, but can be considered a changing feature of the system (Vidal \& Duarte unpubl. data), into which atmospheric-hydrodynamical forces moving sediment resuspension could play a key role.

The adsorption capacity of Alfacs Bay sediments is of great importance for ecosystem management, since freshwater slides on a shallow platform, of less than $1.5 \mathrm{~m}$ depth, when coming into the bay. Sediments contribute to reduce the high SRP concentration, between 1 and $4 \mu \mathrm{M}$, characteristic of freshwater channels, to values below $0.2 \mu \mathrm{M}$, thus acting as an effective regulatory mechanism, whose effectiveness depends on hydrodynamical conditions (see instantaneous adsorption speed in Table 3 , computed from Fig. 7 plots and Table $2 b$ parameters).

The role of sediments in periodic storage of nutrients, coupled to hydrodynamic conditions, has also been pointed out for ammonium (Vidal 1991), although in this case ammonium accumulates in the dissolved pore water pool, and therefore, is more loosely bound to sediment than is phosphorus. The second step of SRP diffusion into particles makes the whole adsorption process partly irreversible (Barrow 1983), so that a fraction of phosphorus is ultimately lost into the sediment, which therefore acts as a phosphorus sink. Enhancement of SRP availability in the water relies on intermittent SRP desorption tied to sediment disturbances. To what extent phytoplankton take advantage of this episodic phenomena depends on their ability to quickly take SRP up and on the degree in which environmental stress allows for the survival of phytoplankton populations.

Acknowledgements. I am grateful to Josep-Anton Morgui and Pilar López for the thorough review of the manuscript and the fruitful discussions. I thank Jordi Rull for helping me with the drawing and for his unconditional support and Jordi Camp for his comments. I also thank Peter Wangersky and 2 anonymous reviewers for helpful suggestions that greatly improved the manuscript. Financial support was provided by CICYT (MAR89-0556) and Caixa de Barcelona grants.

\section{LITERATURE CITED}

Avnimelech, Y., Troeger, B. W., Reed, L. W. (1982). Mutual flocculation of algae and clay: evidence and implications. Science 216: 63-65

Barrow, N. J. (1983). On the reversibility of phosphate sorption by soils. J. Soil Sci. 34: 751-758

Bell, R. T., Ahlgren, I. (1987). Thymidine incorporation and microbial respiration in the surface sediment of a hypereutrophic lake. Limnol. Oceanogr. 32: 476-482

Bolan, N. S., Barrow, N. J., Posner, A. M. (1985). Describing the effect of time on sorption of phosphate by iron and aluminum hydroxyoxides. J. Soil Sci. 36: 187-197

Bostrom, B., Andersen, J. M., Fleischer, S., Jansson, M. (1988). Exchange of phosphorus across the sediment-water interface. Hydrobiologia 170: 229-244

Bowden, J. W., Nagarajah, S., Barrows, N. J., Posner, A. M., Quirk, J. P. (1980). Describing the adsorption of phosphate, citrate, and selenite on a variable-charge mineral surface. Aust. J. Soil Res. 18: 49-60

Boynton, W. R., Kemp, W. M., Osborne, C. G., Kayweyer, K. R., Jenkins, M. C. (1981). Influence of water circulation rate on in situ measurements of benthic community respiration. Mar. Biol. 65: 185-190

Bratbak, G., Dundas, I. (1984). Baterial dry matter content and biomass estimations. Appl. environ. Microbiol. 48: 755-757

Brinkman, A. G. (1993). A double-layer model for ion adsorption onto metal oxides, applied to experimental data and to natural sediments of Lake Veluwe, The Netherlands. Hydrobiologia 253: 31-45

Burkholder, J. M. (1992). Phytoplankton and episodic suspended sediment loading: phosphate partitioning and mechanisms for survival. Limnol. Oceanogr. 37: 974-988

Butler, E. I., Tibbitts, S. (1972). Chemical survey of the Tamar estuary. I. Properties of the waters. J. mar. biol. Ass. U.K. 52: 681-699

Camp, J., Delgado, M. (1987). Hidrografía de las bahías del Delta del Ebro. Inv. Pesq. 51:351-369

Carman, R., Wulff, F. (1989). Adsorption capacity of phosphorus in Baltic Sea sediments. Estuar. coast. Shelf Sci. 29: $447-456$

Carpenter, P. D., Smith, J. D. (1984). Effect of pH, iron and humic acid on behaviour of phosphate. Environ. Tech. Lett. 6: 65-72

Carrit, D. E., Goodgal, S. (1954). Sorption reactions and some ecological implications. Deep Sea Res. 1: 224-243

Chen, Y. S. R., Butler, J. N., Stumm, W. (1973). Kinetic study of phosphate reaction with aluminum oxide and kaolinite. Environ. Sci. Technol. 7: 327-332

Crosby, S. A., Millward, G. E., Butler, E. I., Turner, D. R., Whitfield, M. (1984). Kinetics of phosphate adsorption by iron hydroxides in aqueous systems. Estuar coast. Shelf Sci. 19: $257-270$

Cuker, B. E., Gama, P., Burkholder, J. M. (1990). Type of suspended clay influences lake productivity and phytoplankton response to P loading. Limnol. Oceanogr. 35: 830-839

Davies, J. M. (1975). Energy flow through the benthos in a Scottish Sea loch. Mar. Biol. 31: 353-362

De Groot, W. T. (1981). Phosphate and wind in a shallow lake. Arch. Hydrobiol. 91: 475-489

De Kanel, J., Morse, J. W. (1978). The chemistry of orthophos- 
phate uptake from seawater on to calcite and aragonite. Geochim. Cosmochim. Acta 42: 1335-1340

Delgado, M. (1989). Abundance and distribution of microphytobenthos in the bays of Ebro Delta (Spain). Estuar. coast. Shelf Sci. 29: 183-194

Delgado, M., Camp, J. (1987). Abundancia y distribución de nutrientes inorgánicos disueltos en las bahías del Delta del Ebro. Inv. Pesq. 51: 427-441

Edmond, J. M., Spivack, A., Grant, B. C., Ming-Hui, H., Zexia, C. (1985). Chemical dynamics of the estuary of the Changjiang. Cont. Shelf Res. 4: 17-36

Fox, L. E. (1989). A model for inorganic control of phosphate concentrations in river waters. Geochim. Cosmochim. Acta 53: $417-428$

Fox, L. E. (1991). Phosphorus chemistry in the tidal Hudson River. Geochim. Cosmochim. Acta 55: 1529-1538

Fox, L. E., Sager, S. L., Wofsy, S. C. (1985). Factors controlling the concentrations of soluble phosphorus in the Mississippi estuary. Limnol. Oceanogr. 30: 826-832

Fox, L. E., Sager, S. L., Wofsy, S. C. (1986). The chemical control of soluble phosphorus in the Amazon River and estuary. Geochim. Cosmochim. Acta 50: 783-794

Froelich, P. N. (1988). Kinetic control of dissolved phosphate in natural rivers and estuaries: a primer on the phosphate buffer mechanism. Limnol. Oceanogr. 33: 649-668

Gächter, R., Meyer, J. S., Mares, A. (1988). Contribution of bacteria to release and fixation of phosphorus in lake sediments. Limnol. Oceanogr. 33; 1542-1558

Grasshoff, K., Ehrhardt, M., Kremling, K. (1983). Methods of seawater analysis. Verlag Chemie, Weinheim

Gundersen, J. K., Jorgensen, B. B. (1990). Microstructure of diffusive boundary layers and the oxygen uptake of the sea floor. Nature 345: 604-609

Hall, P. O. J., Anderson, L. G., Rutgers, van der Loeff, M. M. Sundby, B., Westerlund S. F. G. (1989). Oxygen uptake kinetics in the benthic boundary layer. Limnol. Oceanogr. 34: $734-746$

Hamilton, D. P., Mitchell, S. F. (1987). Effects of wind on nitrogen, phosphorus and chlorophyll in a shallow New Zealand lake. Verh. int. Verein. Limnol. 23: 624-628

Heath, R. T., Francko, D. A. (1988). Comparison of phosphorus dynamics in two Oklahoma reservoirs and a natural lake varying in abiogenic turbidity. Can. J. Fish. Aquat. Sci. 45: $1480-1486$

Holdren, G. C. J., Armstrong, D. E. (1980). Factors affecting phosphorus release from intact lake sediment cores. Environ. Sci. Technol. 14: 79-87

Huang, C. P. (1975). Adsorption of phosphate at the hydrous$\mathrm{Al}_{2} \mathrm{O}_{3}$-electrolyte interface. J. Colloid Interface Sci. 53: $178-186$

Jorgensen, B. B., Revsbech, N. P. (1985). Diffusive boundary layers and the oxygen uptake of sediments and detritus. Limnol. Oceanogr 30: 111-122

Kelderman, P. (1984). Sediment water exchange in Lake Grevelingen under different environment conditions. Neth. J. Sea Res. 18: 286-311

Krom, M. D., Berner, R. A. (1980). Adsorption of phosphate in anoxic marine sediments. Limnol. Oceanogr. 25: 797-806

Kros, J. H., Westerveld, E. (1987). Sediment and sedimentwater exchange for phosphorus. Progress Report, The Netherlands Limnological Institute, Nieuwersluis, p. $19-20$

Lebo, M. E. (1991). Particle-bound phosphorus along an urbanized coastal plain estuary. Mar. Chem. 34: 225-246

Lijklema, L. (1980). Interaction of orthophosphate with iron (III) and aluminum hydroxides. Environ. Sci. Technol. 14:537-541

Lucotte, M., d'Anglejan, B. (1983). Forms of phosphorus and phosphorus-iron relationships in the suspended matter of the St. Lawrence Estuary. Can. J. Earth Sci. 20: 1880-1890

Lucotte, M., d'Anglejan. B. (1988). Processes controlling phosphate adsorption by iron hydroxides in estuaries. Chem. Geol. 67: 75-83

Mallo, S., Vallespinós, F., Ferrer, S., Vaqué, D. (1993). Microbial activities in estuarine sediments (Ebro Delta, Spain) influenced by organic influx. Scient. mar. 57: 31-40

Morris, A. W., Bale, A. J., Howland, R. J. M. (1981). Nutrient distributions in an estuary: evidence of chemical precipitatron of dissolved silicate and phosphate. Estuar. coast. Shelf Sci. 12: 205-216

Morse, J. W. (1974). Calculation of diffusive fluxes across the sediment-water interface. J. Geophys. Res. 79: 5045-5048

Parsons, T R., Takahashi, M., Hargrave, B. (1984). Biological oceanographic processes. Pergamon Press, Oxford

Peters, R. H., Cattaneo, A. (1984). The effects of turbulence on phosphorus supply in a shallow bay of Lake Memphremegog. Verh. int. Verein. Limnol 22: 185-189

Pilson, M. E. Q. (1985). Annual cycle of nutrients and chlorophyll in Narragansett Bay, R.I. J. mar. Res. 43: 849-873

Pomeroy, L. R. (1960). Residence times of dissolved phosphate in natural waters. Science 131 1731-1732

Pomeroy, L. R., Smith, E. E., Grant, C. M. (1965). The exchange of phosphate between estuarine waters and sediments. Limnol. Oceanogr. 10: 167-172

Prat, N., Muñoz, I., Camp, J., Comín, F. A., Lucena, J. R., Romero, J., Vidal, M. (1988). Seasonal changes in particulate organic carbon and nitrogen in the river and drainage channels of the Ebro Delta (NE Spain). Verh. int. Verein. Limnol. 23: $1344-1349$

Rahm, L., Svensson, U. (1989). On the mass transfer properties of the benthic boundary layer with an application to oxygen flux. Neth. J. Sea Res. 24: 27-35

Rehm, E. (1985). The distribution of phosphorus in the Weser River Estuary. Environ. Tech. Lett. 6: 53-64

Rippey, B. (1977). The behaviour of phosphorus and silicon in undisturbed cores of Lough Neagh sediments. In: Golterman, H. L. (ed.) Interactions between sediments and fresh water. Junk, Den Haag, p. 348-353

Sharp, J. H., Culberson, C. H., Church, T. M. (1982). The chemistry of the Delaware estuary. General considerations. Limnol. Oceanogr. 27: 1015-1028

Strom, R. N., Biggs, R. B. (1982). Phosphorus distribution in sediments of the Delaware River Estuary. Estuaries 5: 95-101

Upchurch, J. B., Edzwald, J. K. O., Melia, C. R. (1974). Phosphates in sediments of Pamlico Estuary. Environ. Sci. Technol. 8: $56-58$

Van Bennekom, A. J., Berger, G. W., Helder, W., De Uries, R. I P. (1978). Nutrient distribution in the Zaire Estuary and River Plume. Neth. J. Sea Res. 12: 296-323

Vidal, M. (1991). Studies on nutrient dynamics in estuarine systems: nutrient and oxygen sediment-water fluxes. Ph.D. dissertation, Univ. Barcelona

Vidal, M., Morguí, J. A., Latasa, M., Romero, J., Camp, J. (1992). Factors controlling spatial variability in ammonium release within an estuarine bay (Alfacs Bay, Ebro Delta, NW Mediterranean). Hydrobiologia 235/236: 519-525

Vidal, M., Romero, J., Camp, J. (1989). Sediment-water nutrient fluxes: preliminary results of in situ measurements in Alfaques Bay, Ebro River Delta. In: Ros, J. D. (ed.) Topics in marine biology. Scient. mar. 53: 505-511

Watson, S. W., Novitsky, T J., Quinby, H. L., Valois, F. W (1977). Determination of bacterial number and biomass in the marine environment. Appl. environ. Microbiol. 33 $940-946$ 